\title{
Increase in scabies incidence: a retrospective cohort study
}

\author{
Fidan Bener®
}

Department of Dermatology, Darica Farabi Training and Research Hospital, Kocaeli, Turkey

\begin{abstract}
Objectives: Recently, there are studies from many countries reporting that scabies incidence has increased. Similarly, there was an increase in the frequency of scabies admitted to our outpatient clinic. Our aim in this study is to draw attention to the increasing incidence of scabies in our region.

Methods: The cases diagnosed with scabies in dermatology outpatient clinic between 2010-2019, their demographics and treatments were retrospectively analyzed.

Results: It was detected that 949 (0.55\%) scabies cases were diagnosed between 2010-2019. When it was analyzed by years, the 3.5 times increase in cases with scabies in 2014 compared to the previous year was found statistically significant $(p<0.05$ ). When data from 2018 was compared with the data from 2010, an increase in the number of cases by 7.6 times was detected in the outpatient numbers with scabies and by $4.7 / 1000$ person-years times in the general population $(p<0.05)$. Besides, it was determined that the Syrian asylum seekers started to apply to our outpatient clinic as of 2014 , and that the scabies incidence was very high within the same year in these patients (27.6\%). It was detected that permethrin was prescribed by $88.4 \%$ to 868 cases whose treatment details were achieved, and that the ratio of response to treatment was $95.8 \%$.

Conclusions: The results we obtained reveal that there was an increased scabies incidence from 2014 in our region. The necessity to immediately and effectively intervene the affected cases to prevent possible epidemic attacks has formed.
\end{abstract}

Keywords: scabies, dermatology, incidence, scabicide resistance, Syrian asylum seekers

cabies is a common pruritic skin infestation caused by the Sarcoptes scabiei mite [1]. The most common symptom is rash which increases at night [2]. According to Vos et al. [3], more than 200 million people around the world suffer from this ectoparasitic infection. The disease burden affects $0.2 \%$ to $71.4 \%$ of the general population depending on the region [4]. Scabies is a global issue and it is an important cause of morbidity due to its high infectiousness [1]. The infection can spread from person to person via direct skin contact [5]. There are many factors that affect the spread of scabies, including overcrowding, hygiene, age, socioeconomic status, and season [5]. It is critical to know the epidemiological data on this parasite which may easily lead to epidemics, and to take the required measures [6]. In the recent years, there are studies from many countries reporting that scabies incidence has increased [3]. Similarly, there was an increase in the frequency of scabies admitted to our outpatient clinic. We hypothesized that there is an increase in scabies cases in our region. In this study, it is intended to determine the status of scabies in our region by reviewing the outpatient clinic records. 


\section{METHODS}

This study is a hospital-base and retrospective cohort study. The study was approved by the Derince Research and Training Hospital Non-invasive Research Ethics Committee (2019-64 / 8.8.2019). All these procedures were performed in accordance with the principles of the Declaration of Helsinki. The files of the patients who were examined at Dermatology Outpatient Clinic of Darıca Farabi Training and Research Hospital between January 1, 2010 and January 1, 2019 , and who were diagnosed with scabies were reviewed retrospectively.

The control examinations and multiple applications of the same patient for scabies diagnosis were considered as one. The suspected cases were excluded from the study.

\section{Statistical Analysis}

Statistical analyses were performed with SPSS 22
(SPSS Inc., Chicago, Illinois, USA) program. Descriptive statistics were presented by frequencies, percentages, mean \pm standard deviation (min-max) values. The normal distribution of the variables was tested by Kolmogorov smirnov. Comparisons between groups of independent samples were assessed with independent-samples $\mathrm{T}$ test, ANOVA and Z test. Categorical data were compared by Pearson's chi-square test. The results were evaluated in a confidence interval of $95 \%$ and a significance level of $p<0.05$.

\section{RESULTS}

Nine hundred forty-nine $(0.55 \%)$ of 173.136 cases confirmed by dermatoscopy or light microscopy between 2010-2019 were diagnosed with scabies. The mean age of the patients was $29.78 \pm 19.2(0-84)$ years. Among the cases, 546 (57.5\%) were female, $402(42.4 \%)$ were male and the mean age was 31.48

Table 1. Gender distribution based on age groups

\begin{tabular}{lcccccc}
\hline Age & \multicolumn{2}{c}{ Patient } & \multicolumn{2}{c}{ Female } & \multicolumn{2}{c}{ Male } \\
\hline & $\mathrm{n}$ & $\%$ & $\mathrm{n}$ & $\%$ & $\mathrm{n}$ & $\%$ \\
$0-18$ & 341 & 35.9 & 175 & 18.4 & 165 & 17.4 \\
$19-40$ & 334 & 35.2 & 182 & 19.2 & 152 & 16 \\
$41-65$ & 234 & 24.7 & 167 & 17.6 & 67 & 7.1 \\
$>65$ & 40 & 4.2 & 21 & 2.2 & 18 & 1.9 \\
\hline
\end{tabular}

Table 2. Data regarding the cases diagnosed with scabies based on population and number of examination

\begin{tabular}{lccccc}
\hline Years & $\begin{array}{c}\text { Cases diagnosed } \\
\text { with scabies }\end{array}$ & $\begin{array}{c}\text { District } \\
\text { population }\end{array}$ & $\mathbf{1 , 0 0 0}$ Person-years & $\begin{array}{c}\text { Total number of } \\
\text { patients }\end{array}$ & \% \\
\hline 2010 & 34 & 146.896 & 0.23 & 24903 & 0.14 \\
\hline 2011 & 24 & 152.542 & 0.16 & 30167 & 0.08 \\
\hline 2012 & 22 & 157.304 & 0.14 & 11272 & 0.2 \\
\hline 2013 & 42 & 164.385 & 0.26 & 15806 & 0.26 \\
\hline 2014 & 163 & 173.139 & 0.94 & 17859 & 0.91 \\
\hline 2015 & 146 & 182.710 & 0.8 & 17005 & 0.86 \\
\hline 2016 & 127 & 191.123 & 0.66 & 15983 & 0.8 \\
\hline 2017 & 172 & 198.153 & 0.87 & 19634 & 0.88 \\
\hline 2018 & 219 & 201.468 & 1.09 & 20507 & 1.07 \\
\hline Total & 949 & 1.567 .720 & 0.61 & 173136 & 0.55 \\
\hline
\end{tabular}


$\pm 19.2(0-84)$ years, $26.05 \pm 18.75(0-82)$ years, respectively. There was a statistically significant difference between the patient groups in terms of gender and mean age $(p<0.05)$. The mean age of patients with scabies was found to decrease from 33.35 years in 2010 to 26.67 years in $2018(p<0.05)$.

One hundred seven $(12.3 \%)$ scabies cases were detected among 1.192 Syrian asylum seekers examined between 2014-2019, and the mean age of the cases was $18.8 \pm 13.01$ years. When the mean age of all cases and the asylum seekers is compared, the difference was found statistically significant $(p<0.05)$. $78(53.1 \%)$ of the Syrian cases were female, 69 $(46.9 \%)$ were male and the mean age was $20.47 \pm 14.3$ years, $17 \pm 11.2$ years. All patients diagnosed with scabies were analyzed in four groups which are 0-18 years, 19-40 years, 41-65 years and above 65 years (Table 1). $341(35.9 \%)$ of the cases were children and the mean age of them was $9.8 \pm 5.3$ years.

The population of the district, total number of cases, number of cases with scabies, number of cases per 1000 people and the incidence were calculated separately by year (Table 2, Fig. 1). It was detected that the number of cases diagnosed with scabies increased by 3.5 times in 2014 compared to 2013, and this increase was found statistically significant ( $p<$ 0.05). When data from 2018 was compared with the data from 2010, an increase in the number of cases by 7.6 times was detected in the outpatient numbers and by 4.7 times per 1000 people $(p<0.05)$. The incidence of scabies among Syrian asylum seekers in 2014 was $27.6 \%$ and its effect on the overall percentage was $0.13 \%$ (Table 3 ). The prevalence of scabies in asylum seekers between 2014-2018 was 12.33\%, and its effect on the overall percentage was $0.08 \%$. It was found that scabies decreased in the asylum seekers over the years

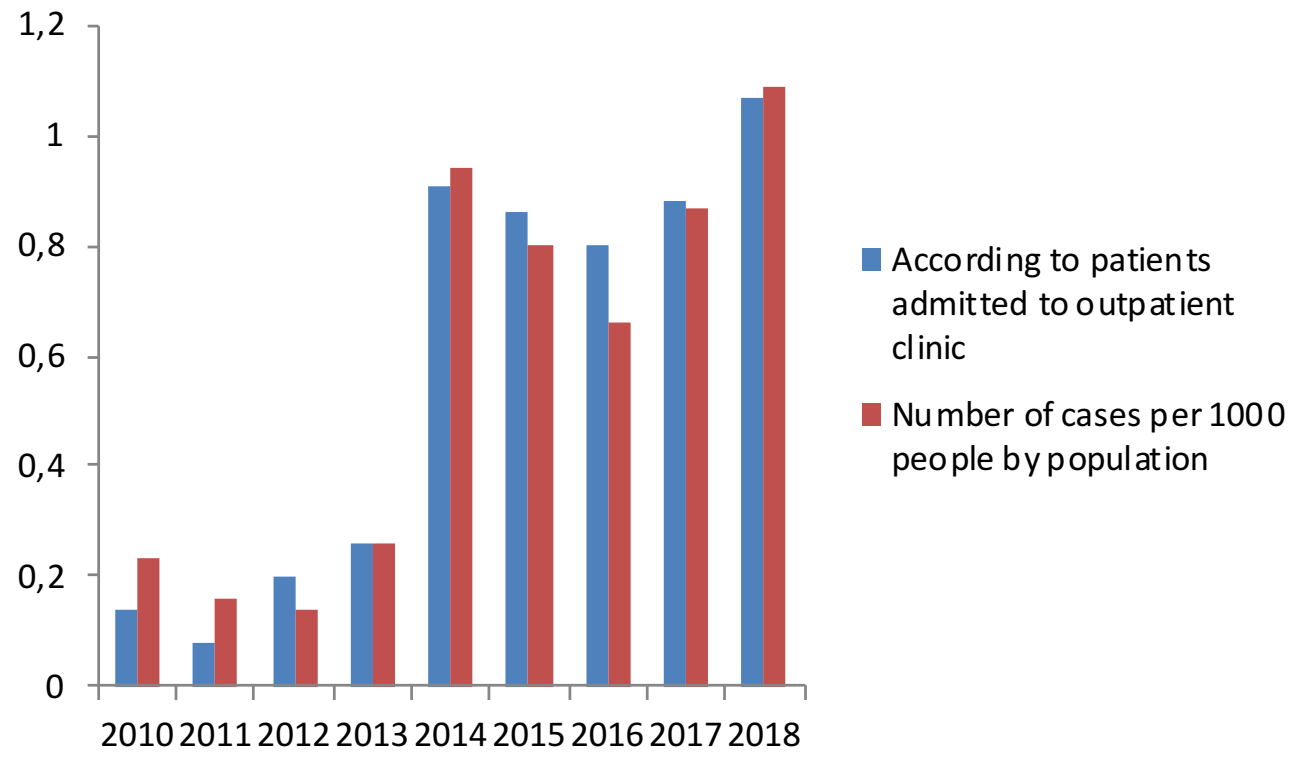

Fig. 1. Scabies incidence by years.

Table 3. Syrian patients diagnosed with scabies by years

\begin{tabular}{lcccc}
\hline Years & Total Syrian cases (n) & \multicolumn{3}{c}{ Syrian cases diagnosed with scabies } \\
\hline & & $\mathrm{n}$ & $\%$ & Effect on overall \% \\
\hline 2014 & 87 & 24 & 27.6 & 0.13 \\
2015 & 112 & 31 & 27.7 & 0.18 \\
2016 & 192 & 26 & 13.5 & 0.17 \\
2017 & 367 & 44 & 12 & 0.22 \\
2018 & 434 & 22 & 5.1 & 0.09 \\
Total & 1192 & 147 & 12.33 & 0.08 \\
\hline
\end{tabular}


Table 4. Ratio of permethrin preference and nonresponse

\begin{tabular}{lcc}
\hline Years & $\begin{array}{c}\text { Ratio of permethrin } \\
\text { preference, } \%\end{array}$ & $\begin{array}{c}\text { Ratio of non-response } \\
\text { to treatment, } \%\end{array}$ \\
\hline 2013 & 95.1 & 2.6 \\
\hline 2014 & 95.7 & 2.6 \\
\hline 2015 & 86.3 & 5.5 \\
\hline 2016 & 92.1 & 4.3 \\
\hline 2017 & 84.3 & 4.1 \\
\hline 2018 & 84 & 4.4 \\
\hline Total & 88.4 & 4.0 \\
\hline
\end{tabular}

and that this decrease was statistically significant ( $p<$ $0.05)$.

From the database, the treatment details of 868 cases in total as of 2013 were achieved. According to this, 767 cases $(88.4 \%)$ were prescribed topical permethrin ( $5 \%$ cream or lotion) in the first examination, 88 cases $(10.1 \%)$ were prescribed benzyl benzoate (20\% cream), 13 cases $(1.5 \%)$ were prescribed topical sulfur ( $10 \%$ ointment). It was determined that 25 cases who were initiated permethrin were prescribed benzyl benzoate and 6 cases were prescribed sulfur due to insufficient treatment. It was determined that 13 cases, who started to take benzyl benzoate during the first treatment without response, were prescribed permethrin and 1 case was prescribed sulfur. According to this, treatment failure for permethrin was $4.0 \%$ and $15.9 \%$ for benzyl benzoate. There was no statistically significant difference in response rates to treatment by years $(p>0.05)$. Topical permethrin treatment preferences and response rates by year are given in Table 4 .

\section{DISCUSSION}

In this study, cases diagnosed with scabies in dermatology outpatient clinic between 2010 and 2019 were retrospectively scanned. The mean age of 949 $(0.55 \%)$ cases with this diagnosis was $29.78 \pm 19.2$ years. Likewise, in the study of Anderson and Strowd [1], the mean age of the cases with scabies was detected as 27 years. In addition, we also found that the mean age of patients with scabies has decreased significantly over the years, similar to the study of Aktaş et al [7]. Although scabies occurs in both genders, while some researches indicate that it is dominant among males, others show that it is more common among females [8]. In our study, it was detected that $57.5 \%$ of the cases were female and $42.4 \%$ were male, and their mean age was $31.48 \pm 19.2$ years, $26.05 \pm$ 18.75 years, respectively. The number of female patients were significantly higher than male patients, and the difference in terms of mean age was statistically significant. A global meta-analysis is recommended in order to understand the role of gender in the global prevalence of scabies better.

The current literature indicates that scabies is more prevalent in the pediatric age group (between 0 to 18 years) than adults [1]. Similarly, in our study the ratio of patients under the age of 18 was higher (35.9\%) compared to other age groups.

When the epidemiological data related to scabies in our country are reviewed, while the prevalence of the disease reported in studies between 1970-2000 varies between $1.74 \%-11.5 \%$, it is seen to be below $1 \%$ in studies conducted after 2000 [9-12] The number of current studies conducted in our country on the epidemiology of scabies is very few. In the retrospective study covering the period between 2006-2017 conducted by Çetinkaya et al. [6] in Kayseri the number of cases per population was at the highest level in 2014. In the retrospective cohort study covering the period 2013-2017 which was conducted by Aktaş et al. [7] in Karabük, the scabies was determined to increase progressively. In our study, it was determined that the number of cases with scabies between 20102013 was below $0.26 \%$ and it increased by 3.5 times in 2014 compared to the previous year and exceeded $0.9 \%$, and this progress continued in the following years.

Recently, many studies from numerous countries reported an increase in the scabies incidence. Sunderkötter et al. [13] reviewed the reports regarding the increased incidence of scabies in Germany. According to this, it was reported that the number of patients treated for scabies increased by $200 \%$ from 2014 to 2016 in Nordrhein region. According to the research by a medical company, the benzyl benzoate and permethrin prescriptions increased by $60 \%$ in 2017 compared to 2016. It was also indicated that the sales of permethrin, allethrin, benzyl benzoate and invermectin group by German pharmacies increased by four times between 2012-2017 [13]. In Nigeria, while the scabies 
incidence in 2012 was $0.85 \%$, it was reported as $6.67 \%$ in 2017 [14]. In Norway, it was reported that the sales of drugs and consultations for scabies increased by three times between 2006-2018 [15].

The increase in scabies incidence was associated with the occurrence of the factors known to support the scabicide resistance, increase in risk groups (children, immunosuppressed and inactive elders, risk groups for sexually transmitted diseases, immigrants and refugees) or increase in prevalence [13]. There are no results to prove this in our age-specific data. A considerable number of Syrian asylum seekers are living in Darıca and neighboring districts. It was determined that the asylum seekers started to apply to our hospital as of the beginning of 2014, and that the scabies was very prevalent among the patients during that year $(27.6 \%)$. The change in economical and socio-cultural background in cases of war and immigration leads to many health problems, especially the infectious diseases [16]. The infectious diseases which previously occurred in certain regions may be transferred to the immigrated area through immigration, and this may lead to the increase of the incidence of the disease [17]. It was reported that 7 thousand 600 scabies cases were recorded in Syria which is affected by the war between $2012-2015$, and that $50 \%$ of the population in Aleppo were affected by the scabies epidemic [18]. Within the context of refugee crisis, the previous observational studies indicate that scabies is one of the most common diseases and the extent to which it may spread [19]. Rapid spread of scabies has been described in Lebanon with regards to migrant populations and asylum seekers, some of which include the time frame of the current Syrian crisis [20]. In a study conducted in Germany, scabies were detected in 16 of 52 patients, $40 \%$ of whom were Syrian asylum seekers [21]. In a similar study conducted in Brussels, in 3907 cases of which $20 \%$ consisted of Syrian asylum seekers, the skin symptoms were detected by $9 \%$ and the majority of the cases were reported to be scabies [22]. In a study conducted in Lebanon in 2013, it was reported that infectious skin diseases including scabies were detected in $47 \%$ of 90 thousand displaced Syrian patients [23]. Although the incidence of scabies among the asylum seekers significantly decreased during the 5-year period when they lived in our region, 2018 data $(5.1 \%)$ show that this is very high for today's conditions and that they are still under threat in terms of sca- bies.

In the treatment of scabies, oral ivermectin, topical permethrin and benzyl benzoate are the most frequently used agents [24]. In our country, oral ivermectin is not licensed. Permethrin is considered as the most preferred treatment in many countries today due to its safety and low toxicity, and the cure ratios vary between $90 \%$ and 98\% [24-27] In our study, it was detected that the efficiency of permethrin was $96.0 \%$. The treatment efficiency for benzyl benzoate was reported as $80 \%$ [24]. We detected this rate as $84.1 \%$. The results we obtained in terms of treatment efficiency comply with the previous clinical studies. Although an in vitro prospective study indicated that mites have increasing tolerance against permethrin, there are no reports validating the in vivo resistance $[13,28,29]$ Based on our six-year successful data, we consider that there is no permethrin resistance and it should be the first choice in scabies treatment. Even though we achieved perfect cure results, we believe that our data should be supported with prospective studies to determine whether the increasing number of cases in our region is associated with the scabicide resistance.

\section{Limitations}

The most important restrictions of our study are its retrospective and single-centered design. Besides, the data is limited to those recorded in the automation system. Failure to reach the treatment data of the cases before applying to a dermatologist, insufficient disease severity data and background information of the cases prevent us from achieving more detailed and objective epidemiological data.

\section{CONCLUSION}

The results we obtained reveal that there is an increased scabies incidence in our region. Although this increase occurred concurrently with the immigration movements, we do not have clear data to explain the actual cause. Based on our six-year data, permethrin is still reliable and efficient in the treatment of scabies. Nevertheless, we believe that our data should be supported with prospective studies to determine the contribution of scabicide resistance to the number of increased cases. 
According to the literature, scabies maintains its global increase and continues to be a public health issue. A necessity to implement an effective central notification system for scabies disease for which notification is not mandatory in our country has formed. A multidisciplinary approach is essential to prevent possible epidemic attacks. Implementing an effective surveillance system may lead to decrease in healthcare cost in addition to improved productivity.

\section{Authors' Contribution}

Study Conception: FB; Study Design: FB; Supervision: FB; Funding: FB; Materials: FB; Data Collection and/or Processing: FB; Statistical Analysis and/or Data Interpretation: FB; Literature Review: FB; Manuscript Preparation: FB and Critical Review: FB.

\section{Conflict of interest}

The authors disclosed no conflict of interest during the preparation or publication of this manuscript.

\section{Financing}

The authors disclosed that they did not receive any grant during conduction or writing of this study.

\section{REFERENCES}

1. Anderson KL, Strowd LC. Epidemiology, diagnosis, and treatment of scabies in a dermatology office. J Am Board Fam Med 2017;30:78-84.

2. Falay T, Gürel MS. [Scabies]. Turkiye Klinikleri J Dermatol Special Topics 2017;10:143-53. [Article in Turkish]

3. Vos T, Allen C, Arora M, Barber RM, Bhutta ZA, Brown A, et al. Global, regional, and national incidence, prevalence, and years lived with disability for 310 diseases and injuries, 1990-2015: a systematic analysis for the global burden of disease study 2015 . Lancet 2016;388:1545-602.

4. Liu JM, Hsu RJ, Chang FW, Yeh CL, Huang CF, Chang ST, et al. Increase the risk of intellectual disability in children with scabies: A nationwide population-based cohort study. Medicine (Baltimore) 2017;96:e7108.

5. Chen JY, Liu JM, Chang FW, Chan H, Cheng KC, Yeh CL, et al. Scabies increased the risk and severity of COPD: a nationwide population-based study. Int J Chron Obstruct Pulmon Dis 2016;11:2171-8.

6. Çetinkaya Ü, Şahin S, Ulutabanca RÖ. The epidemiology of scabies and pediculosis in Kayseri. Turkiye Parazitol Derg 2018;42:134-7.

7. Aktaş H, Cebecik A. Changes in incidence and age distribution of scabies: A retrospective cohort study in a tertiary hospital. Arch
Clin Exp Med 2019;4:21-4.

8. Seyedi Arani HR, Dehghani R, Ghannaee Arani M, Seyyedi Arani HR, Zarghi I. Scabies contamination status in Iran: A review. Int J Epidemiol Res 2016;3:86-94.

9. Pişkin S, Görgülü A, Akgün N, Öztürk A, Şen Ö, Gürkök F. Epidemiology of scabies in Edirne. Balkan Med J 1993;10:15761.

10. Tüzün Y, Kotoğyan A, Cenesizoğlu E, Baransü O, Ozarmağan G, Ural A, et al. The epidemiology of scabies in Turkey. Int J Dermatol 1980;19:41-4.

11. Çiftçi IH, Karaca S, Dogru Ö, Cetinkaya Z, Kulaç M. Prevalence of pediculosis and scabies in preschool nursery children of Afyon, Turkey. Korean J Parasitol 2006;44:95-8.

12. Yılmaz M, Korkmaz E, Karakoç S, Yaztürk Ş, Kizirgil A, Yakupoğulları Y. Investigation of intestinal parasites and ectoparasites in three primary school students in Elazı $\breve{g}$. Türkiye Parazitol Derg 2007;31:139-41.

13. Sunderkötter C, Aebischer A, Neufeld M, Löser C, Kreuter A, Bialek R, et al. Increase of scabies in Germany and development of resistant mites? Evidence and consequences. J Dtsch Dermatol Ges 2019;17:15-23.

14. Onyekonwu CL, Okoh N, Ofondu E, Nwobi E, Onyekonwu CG. Incidence, pattern and trend of scabies infection in Nigeria: A retrospective study of 366 cases. Int J Med Health Dev 2018;23:227-30.

15. Amato E, Dansie LS, Grøneng GM, Blix HS, Bentele H, Veneti L, et al. Increase of scabies infestations, Norway, 2006 to 2018. Euro Surveill 2019;24:190020.

16. İrgil E. Suriyeli sığınmacılarda bulaşıcı olmayan hastalıklar sorunu. In: Savaş, göç ve sağlık. Ankara, Türk Tabipleri Birliği Yayınları; 2016;p.76-82.

17. Öztürk R. Göç ve enfeksiyonlar. Sağlık Düşüncesi ve Tıp Kültürü Dergisi 2014;32:58-9.

18. World Health Organization (WHO). Regional situation report, January 2015 WHO response to the Syrian crisis. Available at: http://www.who.int/hac/crises/syr/sitreps/en/ Accessed December 8, 2018.

19. Greco D, Caputo SL, Binkin N, Panatta M, Squarcione S, Germinario C. Health response to a large and rapid influx of Albanian refugees in southern Italy, 1991. Disasters 1993;17:61-9. 20. Kawa N, Hanna E and Bizri AR. Transmissible dermatological diseases affecting Syrian refugees in Lebanon. J Refug Glob Health 2019;2:4

21. Wollina U, Gaber B, Mansour R, Langner D, Hansel G, Koch A. Dermatologic challenges of health care for displaced people. Lessons from a German emergency refugee camp. Our Dermatol Online 2016;7:136-8.

22. van Berlaer G, Bohle Carbonell F, Manantsoa S, de Béthune X, Buyl R, Debacker M, et al. A refugee camp in the centre of Europe: clinical characteristics of asylum seekers arriving in Brussels. BMJ Open 2016;6:e013963.

23. Refaat M, Mohanna K. Syrian refugees in Lebanon: facts and solutions. Lancet 2013;382:763-4.

24. Abdel-Raheem TA, Méabed EM, Nasef GA, Abdel Wahed WY, Rohaim RM. Efficacy, acceptability and cost effectiveness of four therapeutic agents for treatment of scabies. J Dermatolog Treat 2016;27:473-9. 
25. Strong M, Johnstone P. Interventions for treating scabies. Cochrane Database Syst Rev 2007;3:CD000320.

26. Elgart ML. Cost-benefit analysis of ivermectin, permethrin and benzyl benzoate in the management of infantile and childhood scabies. Expert Opin Pharmacother 2003;4:1521-4.

27. Bagati KD, Agarwal P, Sharma J. A comparative study to assess the efficacy of permethrin (topical) and benzyl benzoate (topical) for the treatment of scabies patients. Int J Res Pharm
Sci 2019;10:3688-93.

28. Pasay C, Arlian L, Morgan M, Vyszenski Moher D, Rose A, Holt D, et al. High-resolution melt analysis for the detection of a mutation associated with permethrin resistance in a population of scabies mites. Med Vet Entomol 2008;22:82-8.

29. Khalil S, Abbas O, Kibbi AG, Kurban M. Scabies in the age of increasing drug resistance. PLoS Negl Trop Dis 2017;11:e0005920. 